\title{
Job Satisfaction and Quality of Healthcare Delivery: A Cross-Sectional Study in Ogun State Hospitals Management Board, Nigeria
}

\author{
Ahmed Babatunde Jimoh ${ }^{1}$, Oluwafemi Tinuola ${ }^{2}$ \\ ${ }^{1}$ State Hospital, Ilaro, Ogun State Hospitals Management Board, Nigeria \\ ${ }^{2}$ Adjunct Professor, School of Public Health Programs, Texila American University, Guyana, \\ South America
}

\begin{abstract}
Job satisfaction is vitally necessary in the daily life of the workforce, and the essential elements, materials and mechanism that drives job satisfaction demand great attention. At present, the situation of healthcare workers in the employment of Ogun State Hospitals Management Board, Nigeria, seems to be less satisfied with the policies of the healthcare institutions. The study examined job satisfaction and the quality of healthcare delivery in Ogun State Hospitals Management Board (HMB) in Nigeria. This study adopted a cross-sectional design method and was conducted among the healthcare professionals in the study area. A total of 729 copies of a well-structured questionnaire were administered using a multi-staged sampling technique to obtain information from all the available healthcare professionals in the study area. Data collected were analysed using descriptive statistics. Findings of this study revealed that $12.5 \%$ of healthcare professionals in Ogun State Hospitals strongly agreed, 21.9\% moderately, and 32\% slightly agreed with the level of satisfaction of the leadership and management styles. $25.7 \%$ of the healthcare professionals disagreed (7.4\% strongly, $4.0 \%$ moderately and $14.3 \%$ slightly) that they would recommend employment in the study area. The results further revealed that $47.9 \%$ of healthcare workers had a low level of job satisfaction that could lead to many factors. In addendum, $43.6 \%$ of the respondents believed that the healthcare delivery was not low but with moderate quality. The study concluded that majority of the healthcare workers had low level of job satisfaction. The quality of healthcare delivery is of medium quality. Finally, this study recommends that there should be an establishment of health and life insurance for health workers; improved health infrastructures; conducive work environment and working conditions; job security; regular and continuous training of healthcare professionals; and attractive rewards and compensation.
\end{abstract}

Keywords: Job satisfaction, Management Board, Nigeria, Ogun State Hospitals, Quality of healthcare delivery.

\section{Introduction}

Health care workers are crucial for health service delivery and the provision of quality care to patients [1]. They also contribute significantly to the healthcare system in most countries. Researchers and individuals have defined job satisfaction based on their understanding. In other words, job satisfaction is a term that describes how happy or content an employee is with his or her work [2]. The fruition, fulfilment, and pleasure that come from work could be regarded as job satisfaction. Quality healthcare delivery, on the other hand, has been linked to healthcare workers' job satisfaction, organizational commitment, and subsequent intention to remain employed.

Studies state that job satisfaction of the health workers is very important in building up employees' motivation and efficiency as it limits better employee performance and higher level of patient's satisfaction [3, 4]. In contrast, job 
dissatisfaction would definitely result in burnout and staff turnover, which could aggravate under staffing of health facilities [5].

In the health sector, job satisfaction is highly associated with quality of services and patient satisfaction [6]. It is believed that job satisfaction is a key factor that influences the performance of individuals and organizations [7]. Considering a significant factor that impacts the quality and/or productivity of human resources is job satisfaction. It also determines the extent to which employees in an organization like or dislike their jobs.

Job satisfaction and quality of healthcare workers service delivery in developing countries in general and in Nigeria, in particular, is very low. In recent times, healthcare professionals moved from the Ogun State Hospitals Management Board to Tertiary Hospitals owned by the Federal Government within the State. Surveys have shown that the numbers of healthcare professionals employed by the State's HMB would decline by half within a year of their employment due to seeking greener pastures elsewhere. This has led to progressive staff attrition with resulting work overload and stress for the healthcare professionals left in the service that cannot efficiently and effectively deliver quality healthcare service to the populace.

In addition, patients visiting the hospital on delay in accessing services have made several complaints, as they have to wait for long hours, cope with the attitude of overstretched healthcare professionals, lack of doctors on sit and many more, which could be attributed to acute shortage of human resources. A number of factors called "dynamic factors" affect health services [8, 9]. Previous studies conducted in Nigeria addressed job satisfaction of health workers [2, 8, 10-12].

The dearth of healthcare professionals in the country at large and Ogun state specifically calls for concern. In the less developed nations, WHO (2006) posited that most countries have less than $50 \%$ of the required healthcare service providers to provide health care in most of their health institutions while utilizing non-qualified workers to provide health care services [13]. In Ogun State, which is the study area, the Healthcare professionals in the employment are leaving the services dues to some reasons, which include but are not limited to difficult working conditions, work overload and poor remuneration compared to Federal Health Institution in the State.

Consequently, the continuation of this phenomenon may affect the delivery of healthcare services in the State. The magnitudes of unsatisfied healthcare service providers on access to quality care, professional misconduct, effective and efficient healthcare delivery, attitude to patients and the overall healthcare system is too grave to overlook by any Government or healthcare managers. Research on the satisfaction of healthcare professionals is critical to management of healthcare system.

However, there has been little or no study on the job satisfaction of healthcare professionals working in the hospitals under Ogun State Hospitals Management Board. It was in this light that this study focused on the level of job satisfaction and quality of healthcare professionals' delivery in the hospitals under Ogun State Hospitals Management Board of Nigeria.

\section{Materials and Methods}

The study area was confined to Ogun State Hospitals Management Board (HMB), which is found in Ogun State, Nigeria (Figure.1). Its headquarters is situated at Block A, State Secretariat Complex, Koeman, Abeokuta. The military Government, with the objective to provide effective, qualitative, and quantitative healthcare services to the people of Ogun State, established the agency in 1978. The Ogun HMB has five (5) zonal offices (Abeokuta, Ijebu Ode, Ota, Sagamu and Ilaro Health Zones). In the study are, there are Five (5) State Hospitals, Five (5) Dental Centres, Four (4) Community Mental Health Centres and Twenty-five (25) General Hospitals with a total of Thirty-Nine (39) Health 
facilities [14]. The study population consists of healthcare professionals in the employment of Ogun State Hospitals Management Board. Their population include 196 Doctors and Dentist, 711 Nurses, 64 Pharmacist, 47 Pharmacy technicians, 68 Medical Laboratory Scientists, 46 Medical Laboratory Technologist, 34 Physiotherapist, $25 \quad$ Dental Technologists/Therapists and 3 Radiographers (Department of Planning Research and Statistics, Ogun HMB, 2019).

The Method employed in this study involved a cross-sectional descriptive study design, and it was conducted among the healthcare professionals in Ogun State Hospitals, Nigeria. A multi-stage sampling technique was adopted to obtain relevant information from the healthcare professionals. The study adopted the use of systemic sampling techniques in this work to select the Departments of respective medical personnel required to provide answers to several questions. In the second stage of selection, purposive and total sampling technique to select actual participants in the different departments.

When the actual number of healthcare workers was insufficient, all the available healthcare workers (729) were used as the sample size. The determination of the sample size involves disregarding sampling error [15]. Data were collected mainly with a selfadministered structured and unstructured questionnaire in the thirty-nine (39) health facilities comprising all the twenty (20) Local Government Areas in Ogun State. A total of 729 copies of a well-structured questionnaire were administered using a multi-stage sampling technique from all available healthcare professionals. All the copies of the questionnaire were retrieved and coded for the analysis using descriptive statistics, while the results were presented in frequencies tables, graphs, and charts.

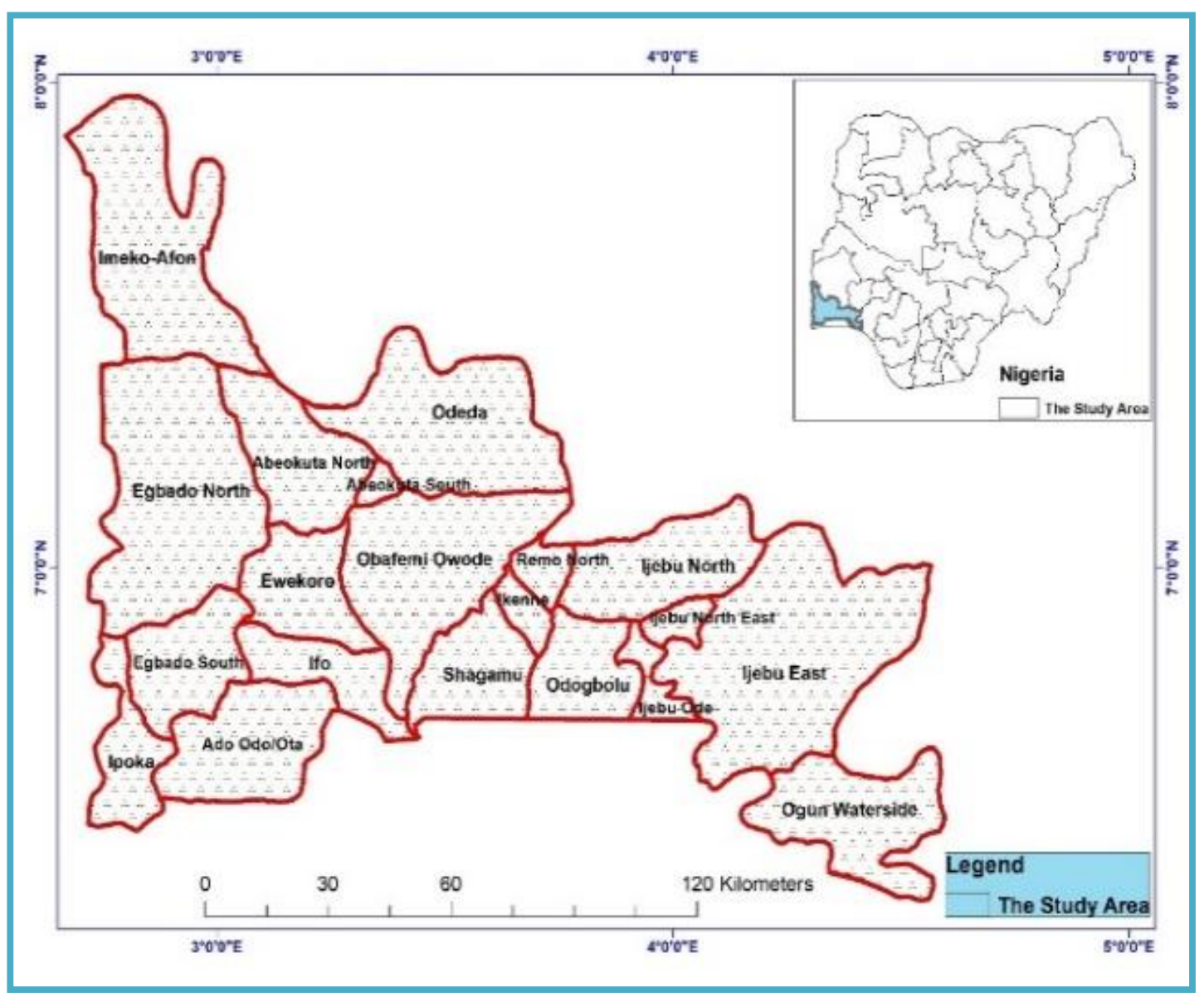

Figure 1. Ogun State, the Study Area 


\section{Results}

\section{Demographic Characteristics of the Respondents}

The demographic characteristics of the healthcare professionals are presented in Table 1 and Figure 2-3. Most of the healthcare professionals were female (73.5\%), and $83.0 \%$ of them were married (Table 1). Majority of the healthcare professionals were between the ages 31 and 50, representing $70 \%$ of the total healthcare professionals in Ogun State Hospitals. $83.1 \%$ of the healthcare professionals were single, while the least percentage constituted those who have divorced with a percentage of $1.2 \%$. The number of respondents with university education constituted a larger percentage with $56.5 \%$, while non-graduate respondents constituted a total of 197 (27.0\%). The Nurses were the majority of healthcare workers constituting a total of $388(53.2 \%)$ of the respondent, followed by the Doctors 110 (15.1\%) and other professional in Ogun State Hospitals Management Board (Table 1). A very small number of respondents, which represents $11.2 \%$, have spent more than 20 years, while $36.1 \%$ and $30.0 \%$ of the respondents indicated to have spent between 10-20 and less than 5 years in the study area (Figure 3).

Table 1. Demographic Characteristics of the Respondents

\begin{tabular}{|c|c|c|c|}
\hline \multicolumn{2}{|c|}{ Demographic Characteristics } & \multirow{2}{*}{$\begin{array}{l}\text { Frequency }(\mathbf{N}=\mathbf{7 2 9}) \\
193\end{array}$} & \multirow{2}{*}{$\begin{array}{l}\text { Percent } \\
26.5 \\
\end{array}$} \\
\hline Gender & Male & & \\
\hline & Female & 536 & 73.5 \\
\hline \multirow[t]{4}{*}{ Age Bracket } & Less than 30 & 112 & 15.4 \\
\hline & $31-40$ & 261 & 35.8 \\
\hline & $41-50$ & 249 & 34.2 \\
\hline & 50 and above & 107 & 14.7 \\
\hline \multirow[t]{4}{*}{ Marital Status } & Married & 606 & 83.1 \\
\hline & Unmarried & 99 & 13.6 \\
\hline & Divorced & 9 & 1.2 \\
\hline & Widowed & 15 & 2.1 \\
\hline \multirow[t]{3}{*}{ Education Level } & Diploma & 197 & 27.0 \\
\hline & Graduate & 412 & 56.5 \\
\hline & Postgraduate & 120 & 16.5 \\
\hline \multirow[t]{15}{*}{ Profession } & Doctor & 110 & 15.1 \\
\hline & Dentist & 20 & 2.7 \\
\hline & Nurse & 388 & 53.2 \\
\hline & Pharmacist & 37 & 5.1 \\
\hline & Medlab Scientist & 35 & 4.8 \\
\hline & Physiotherapist & 16 & 2.2 \\
\hline & Dietician/Nutritionist & 13 & 1.8 \\
\hline & Lab Technician & 44 & 6.0 \\
\hline & Pharm. Technician & 38 & 5.2 \\
\hline & Dental Assistant/Therapist & 14 & 1.9 \\
\hline & Radiographer & 4 & 0.5 \\
\hline & Dental Technologist & 5 & 0.7 \\
\hline & Optometrist & 2 & 0.3 \\
\hline & X-ray Technician & 3 & 0.4 \\
\hline & Total & 729 & 100.0 \\
\hline
\end{tabular}




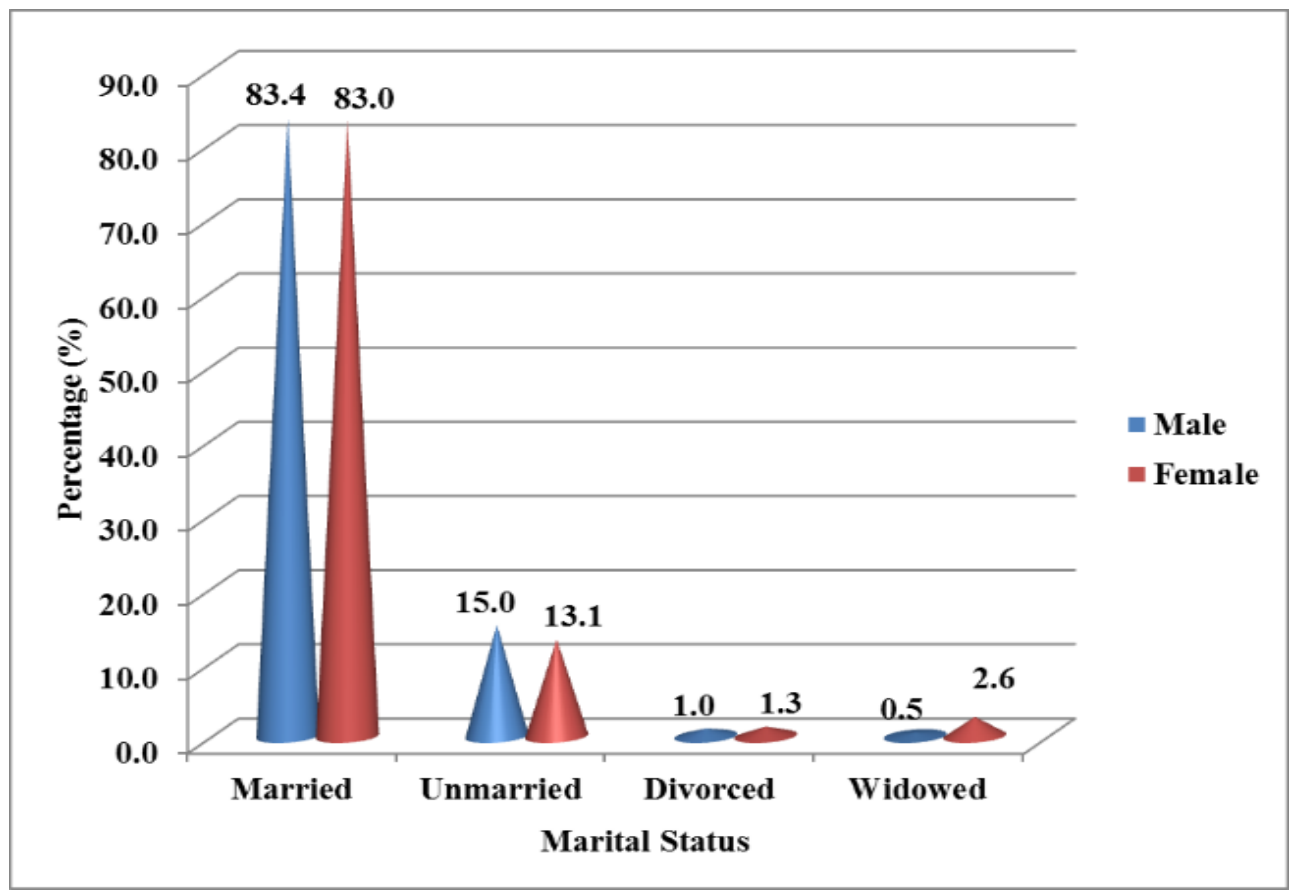

Figure 2. Percentages of Respondents with Marital Status

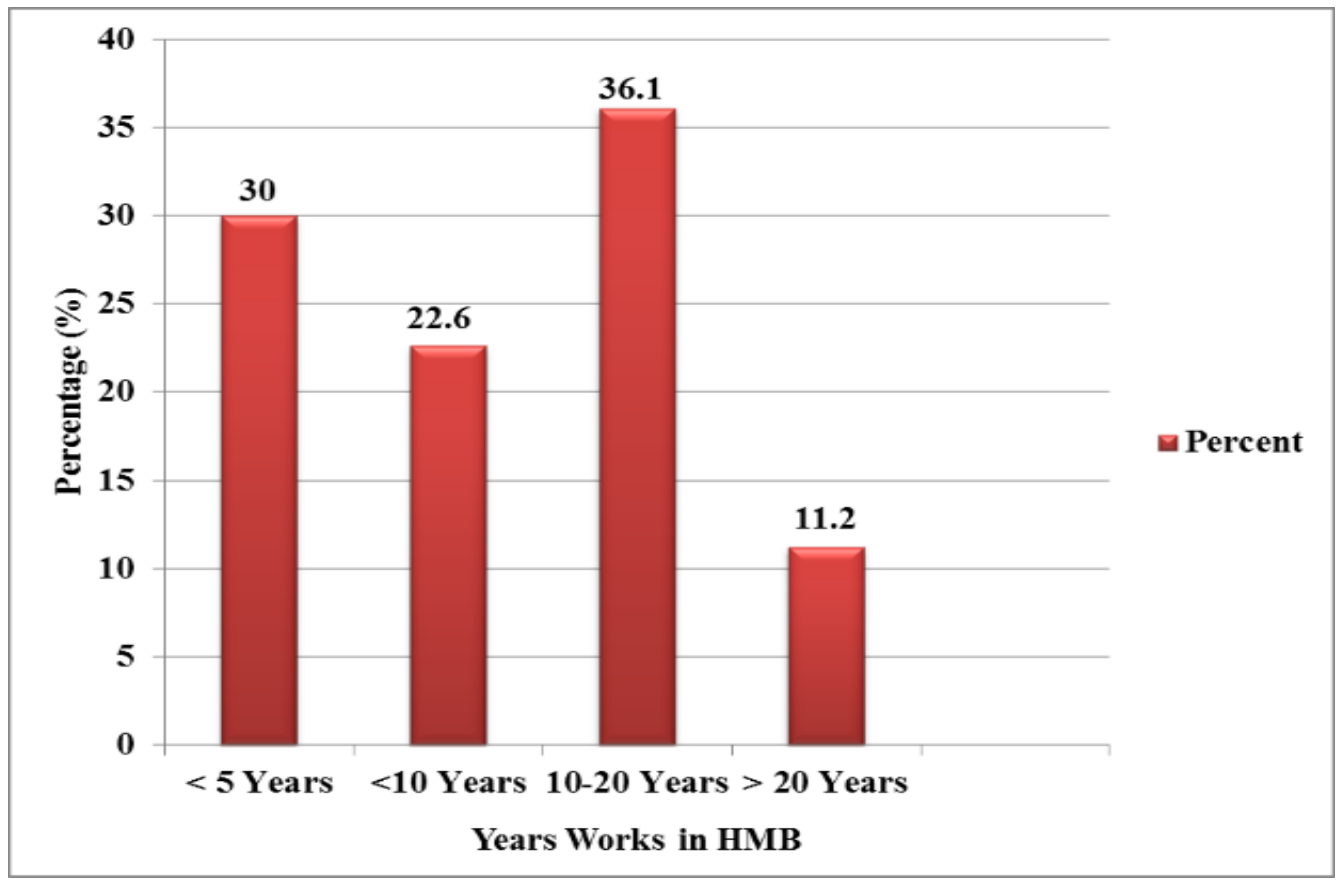

Figure 3. Distribution of the Years spent in service of the HMB

\section{Level of Job Satisfaction by Healthcare Workers in the Study Area}

Table 2 represents the perception of healthcare workers on the overall satisfaction of job in Ogun State Hospitals Management Board. A very large number of healthcare workers, $233(32.0 \%)$, slightly agreed that they were satisfied with the leadership and management styles of the HMB, while the $8.1 \%$, which represent a total of 59 healthcare workers, strongly disagreed with the leadership and management styles of job satisfaction in the Ogun State Hospitals Management Board. A very small proportion of Healthcare workers, $39(5.3 \%)$ in Ogun State Management Board, moderately disagreed that they do not have confident with the leadership of their facilities, 
while a large number, 241 (33.1\%), slightly agreed that they were satisfied with Ogun State Hospitals Management Board. While 7.4\% of the healthcare workers strongly disagreed that they would recommend employment at Ogun State Hospitals Management Board to friends, $12.8 \%$ of the healthcare workers strongly agreed that they could choose an employer again if they would choose to work in Ogun State Hospitals Management Board. Based on the above findings, it is clearly shown that healthcare workers in Ogun State Management Board were averagely satisfied with their job.

Figure 4 shows the rating and/or degree of job satisfaction by healthcare workers in Ogun State
Hospitals Management Board. Distribution based on the degree of job satisfaction shows that the majority has a low level of job satisfaction with a total of 3349 respondents, which represents $47.9 \%$, followed by the medium $(38.5 \%)$, and the least percentage (13.6\%) constitutes the proportion of the healthcare workers with high job satisfaction in Ogun State Hospitals Management Board. This signifies that larger number of healthcare workers have low level of job satisfaction which could lead to many factors such as quality of healthcare delivery, leaving the job for better ones, to mention but a few.

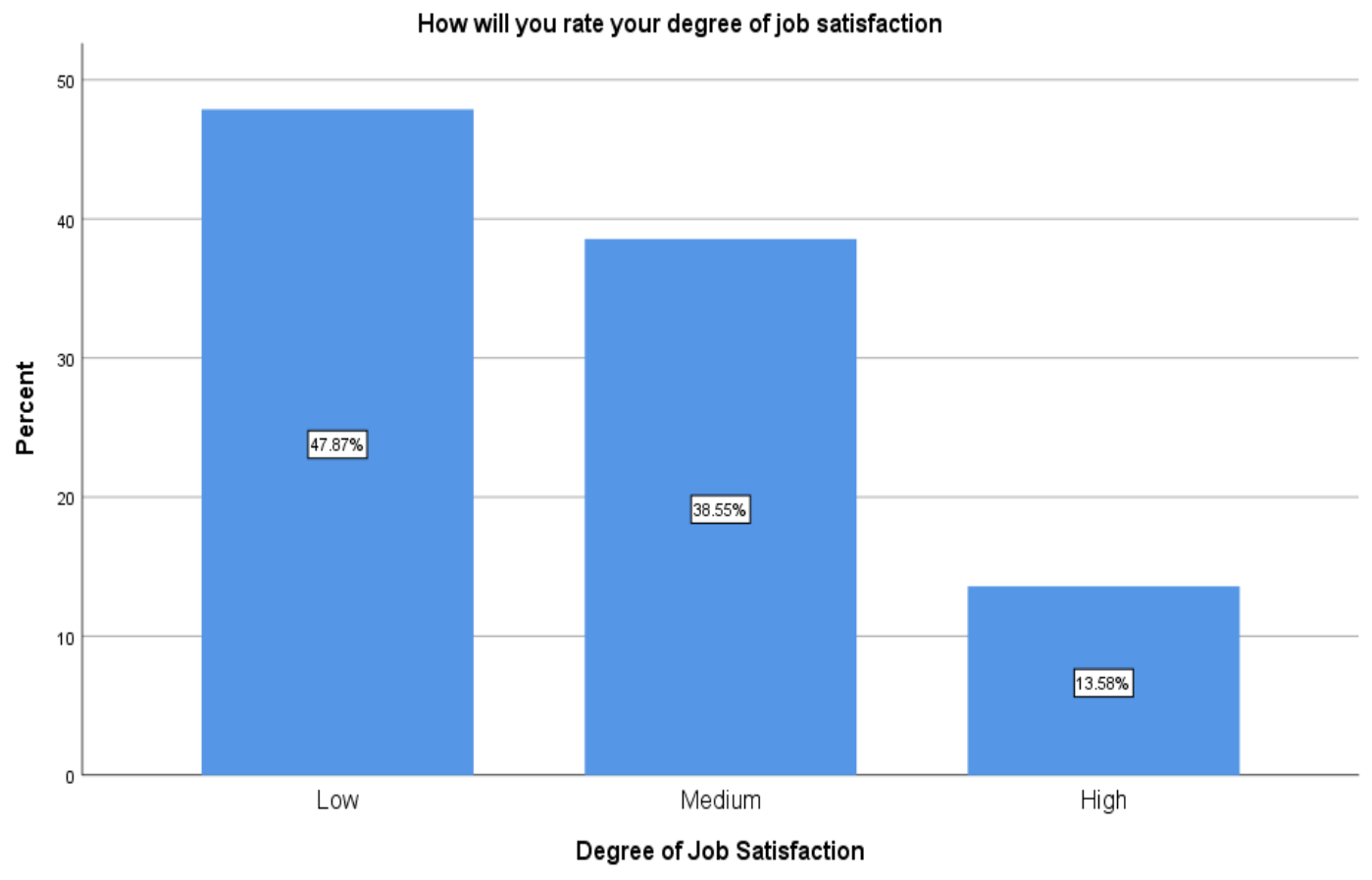

Figure 4. Distribution of the Degree of Job Satisfaction

Figure 5 presents major reasons for the low level of job satisfaction in the employment of Ogun State Hospitals Management Board. Only very small proportions of healthcare workers identified 'Training capacity building and career development' and 'Regular provision of PPE' as reasons for rating the high degree/level of job satisfaction in the study area. This implies that the Ogun State Hospitals Management Board performed very well in the training of their healthcare workers and the regular provision of PPE in the various health facilities found in the study area. 


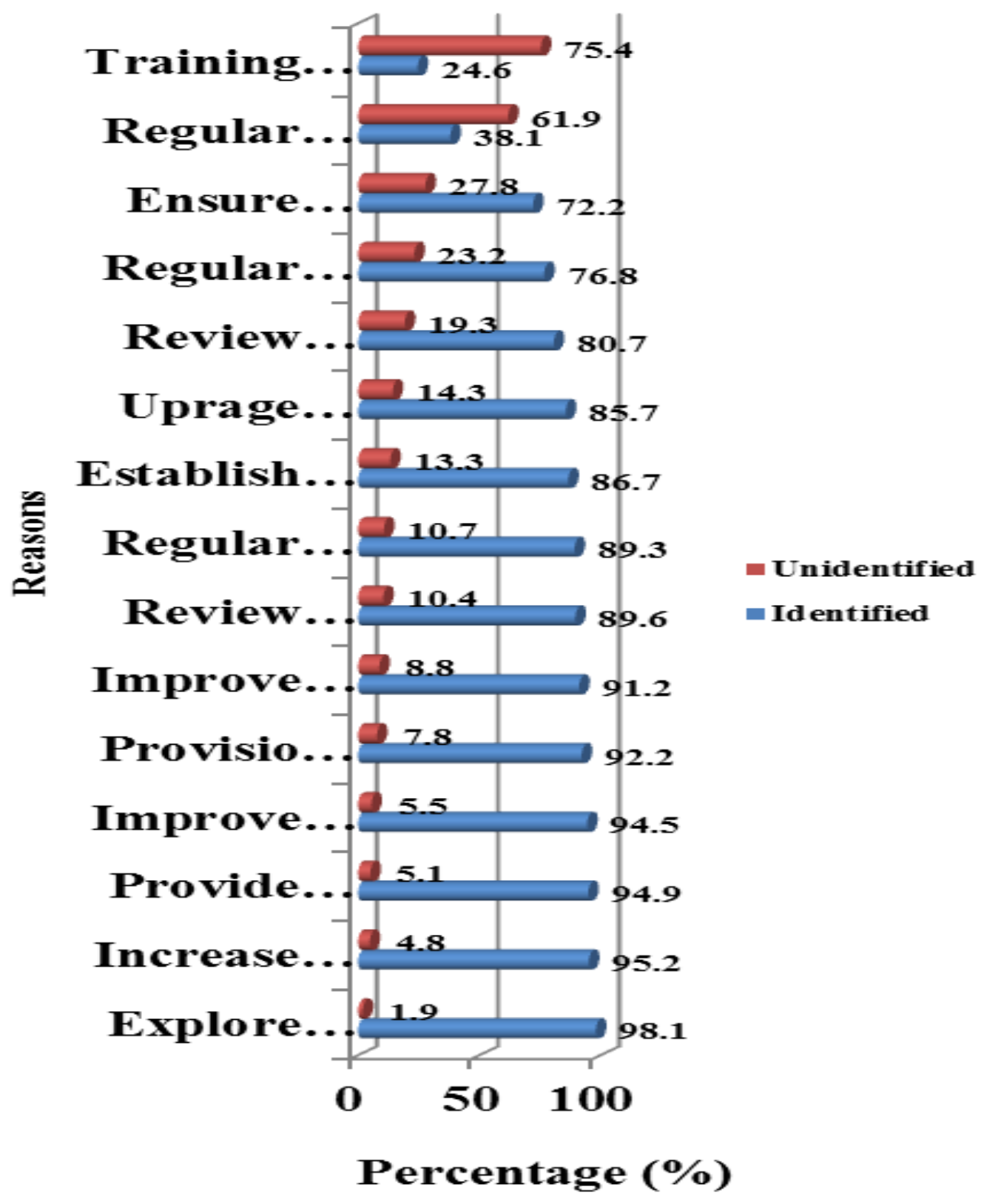

Figure 5. Reasons for the Degree/Level of Job Satisfaction in Ogun State Hospitals Management 


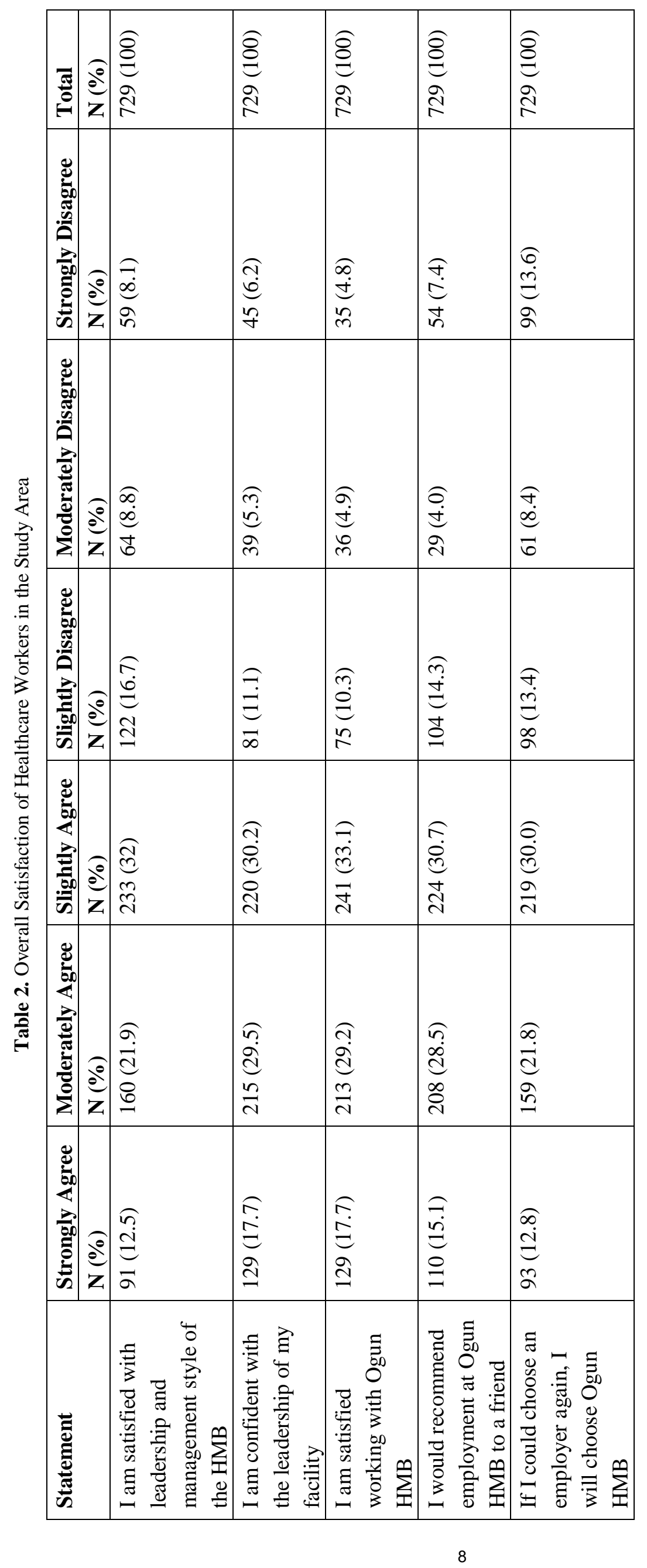




\section{Qualities of Healthcare Delivered by Healthcare Workers in the Study Area}

The perception of healthcare workers on the quality of healthcare deliverer which are categorized into low, medium, and high, is presented in Figure 6. Majority of the respondents, $318(43.6 \%)$, indicated that the healthcare services delivered were moderate, which falls within the category of the medium. $28.9 \%$ of the respondents believed that the quality of services was low, while only $27.4 \%$ with the low quality of health services delivered by the healthcare workers in Ogun State Hospitals Management Board. In general, larger proportions of the respondents believed that the healthcare delivery was not low; $27.4 \%$ of high quality and $43.6 \%$ of medium/moderate quality.

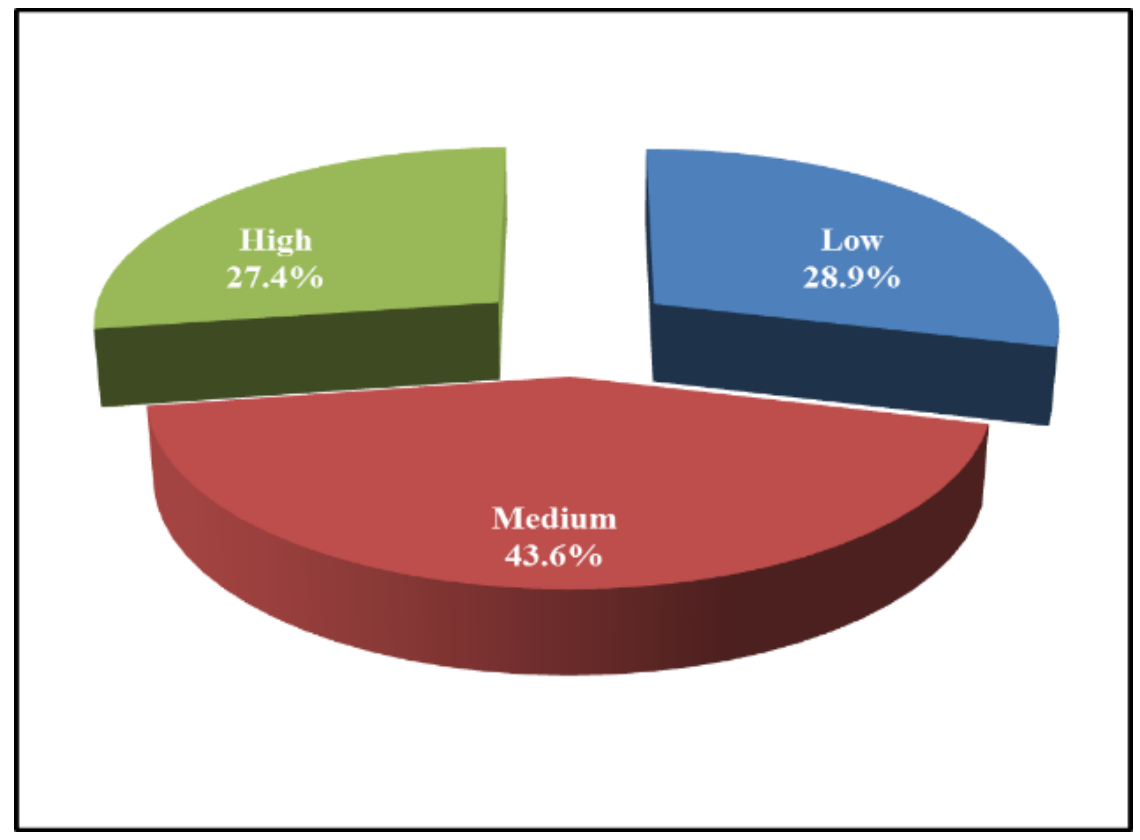

Figure 6. Distribution of the Quality of Healthcare Delivery

\section{Discussion}

The level of job satisfaction was viewed in relation to the leadership and management style of the HMB, the confidence of the healthcare workers with the leadership of the facilities, satisfaction working for HMB, their recommendation of HMB and overall level of job satisfaction. The level of job satisfaction among healthcare workers in the study area revealed $47.9 \%$ had a low level of job satisfaction $13.6 \%$ showed a high level of job satisfaction and $38.5 \%$ of medium level of job satisfaction. In comparison to other studies, a study among medical doctors in Benin, Nigeria $54 \%$ was dissatisfied with their jobs while $30 \%$ are satisfied [16]. Another study among nurses in Ekiti revealed $67.1 \%$ with the low level of job satisfaction, and $3.1 \%$ with a high level of job satisfaction [8], physicians in Pakistan 56\% were not satisfied with their jobs [17] and health workers in Ethiopia showed $65.1 \%$ were dissatisfied with their jobs [5]. Other studies where healthcare workers show majority were dissatisfied with their jobs include study among radiographers in South-Eastern, Nigeria (56.3\%) [18], physicians and nurses in Yenagoa (57.5\%) [19], Jos (64.8\%) [20], North-Eastern (68.2\%) [21], Owo, (78.5\%) [22] and Kano (80.1\%) [23]. [1] assessed the level of job satisfaction and associated factors among health care professionals working at the University of Gonder Referral Hospital, Northwest Ethiopia. In the study, it was observed that the overall level of satisfaction was 54\%.

Furthermore, this study found that the low level of job satisfaction could be due to many factors such as quality of small proportions of healthcare workers identified 'Training capacity 
building and career development and 'Regular provision of PPE' as reasons for rating the degree/level of job satisfaction high in the study area. This implies that the Ogun State Hospitals Management Board performed very well in the training of their healthcare workers and the regular provision of PPE in the various health facilities found in the study area. The findings of this study also corroborate the study of [2]. Similar findings were obtained in Eastern Ethiopia [7] and South Africa [24], Saudi Arabia [25] and India [26]. Another study done in Saudi Arabia reported a job satisfaction prevalence of 97.0\% [27]. Also, [28] state that the healthcare workers were least satisfied with remuneration, freedom of working method, material and equipment availability and the possibility of career advancement.

The study revealed that the quality of healthcare delivered was moderate, which falls within the category of medium according to $43.6 \%$ of the respondents. $28.9 \%$ of respondents opined the quality of healthcare delivery to be low and $27.4 \%$ high. $71 \%$ of the respondents concluded that the quality of healthcare varies between high and medium, which justifies that healthcare delivery was not low. The stated null hypothesis "no significant difference in the level of job satisfaction of healthcare workers and the quality of healthcare delivery" was rejected due to the statistical significance of the results.

\section{Conclusion}

Overall job satisfaction and the quality of healthcare workers delivery have been examined. Findings of this study revealed that the majority of healthcare professionals in Ogun State Hospitals were satisfied with the leadership and management styles. A very small proportion of the healthcare professionals strongly disagreed that they would recommend employment in the study area. In terms of the level of job satisfaction by the healthcare workers in the study are, a larger number of healthcare workers had low level of job satisfaction which could lead to many factors such as quality of healthcare delivery, leaving the job for better ones to mention but a few. In addition, larger proportions of the respondents believed that the healthcare delivery was not low but with moderate quality. Finally, this study recommends that there should be an establishment of health and life insurance for health workers; improved health infrastructures; conducive work environment and working conditions; job security; regular and continuous training of healthcare professionals; and attractive rewards and compensation.

\section{Conflict of Interest}

We have no conflict of interest to declare.

\section{Acknowledgements}

The author expresses his gratitude to all healthcare workers and the Department of Research Planning and Statistics (HMB) for their willingness and cooperation to participate in this study. 


\section{References}

[1] Getnet, G., Yetnayet, S., Animut, A., and Yihalem, A.B., 2018, Level of Job Satisfaction and Associated factors among health care professionals working at University of Gonder Referral Hospital, Northwest Ethiopia: A cross-sectional study. BMC Res Notes, 11, 824. https://doi.org/10.1186/s13104018-3918-0.

[2] Kadiri-Eneh, N.P., Uzochukwu, B.S., TobinWest, C., and Azuike, E.C., 2018, An assessment of job satisfaction among primary health care workers in rivers state, Nigeria. Nigerian Journal of Medicine, 27(3), 282-291. DOI: 10.4103/1115-2613.278792.

[3] Willis-Shattuck, M., Bidwell, P., Thomas, S., Wyness, L., Blaauw, D., and Ditlopo, P., 2008, Motivation and retention of health workers in developing countries: a systematic review. $B M C$ Health Serves, 4(8), 247. DOI: 10.1186/1472-69638-247.

[4] Alemshet, Y., Leja, H., Alima, H., Challi, J., and Morankar, S., 2011, Job satisfaction and its determinants among health workers in Jimma University Specialized Hospital, Southwest Ethiopia. Ethiop. J Health Sci., Aug; 21(Suppl 1), 19-27.

[5] Mulugeta, M.M., and Ayele, G.B., 2015, Factors associated to job satisfaction among healthcare workers at public hospitals of West Shoa Zone, Oromia Regional State, Ethiopia: A Cross Sectional Study. Science Journal of Public Health, 3(2), 161167.

[6] Liu, J.A., and Qi, W.Z., 2010, Job satisfaction and its modeling among township health center employees: a quantitative study in poor rural China. BMC Health Serv Res., 10,115. Doi: 10.1186/14726963-10-115.

[7] Ayele, G., Negga, B., Gudina, E.A., and Yadeta, D., 2015, Job satisfaction and associated factors among health care providers at public health institutions in Harari region, eastern Ethiopia: a cross-sectional study. BMC Res Notes, 8, 1-7. DOI 10.1186/s13104-015-1368-5.

[8] Ayamolowo, S.J., Irinloye, O., and Oladoyin, M.O., 2013, Job Satisfaction and Work Environment of Primary Health Care Nurses in Ekiti State, Nigeria: An Exploratory Study. International Journal of Caring Sciences, 6 (3), 531-542.
[9] Raja, M.A., and Faraz, A.W., 2013, Factors influencing job satisfaction in public healthcare sector of Pakistan. Global Journal of Management and Business Research Administration and Management, 13(8), 60-66.

[10] Adeniran, A.A., Oluwole, E.O., and Ojo, O.Y., 2021, Job satisfaction and intention of primary health care workers to leave: A cross-sectional study in local government area in Lagos, Nigeria. Global Journal of Health Science, 13(4),138. DOI:10.5539/gjhs.v13n4p138-149.

[11] Okeke, H.C., Bassey, P., Oduwole, O.A., and Adindu, A., 2020, Client characteristics and satisfaction with the quality of primary health-care services in Calabar, Nigeria. Calabar Journal of Health Sciences, 3(1), 1-8.

[12] Goodman, O.O., Aderibigbe, S.A., Sekoni, O.O., Olatona, F.A., and Kuyinu, Y.A., 2016, Effect of health workers sensitization on satisfaction with immunization services among mothers of under-fives in Ilorin, North Central Nigeria. Res. J. of Health Sci., 4(4), 304-315. DOI: 10.4314/rejhs.v4i4.6.

[13] World Health Organization (2006). World health report 2006. Working together for health. Geneva, World Health Organization http://www.who.int/whr/2006/en/. Accessed 25 April 2020).

[14]Department of Planning Research and Statistics (DPRS), 2019, Ogun State Hospitals Management Board, Ogun State, Nigeria. https://www.ogunstate.gov.ng/ohmb/.

[15] Salami, A.A., Olanrewaju, R.M., and Tilakasiri, S.L., 2016, Perception and awareness of climate change in Osogbo Metropolis, Nigeria. Journal of World Development Studies, 2(2), 111-127.

[16] Ofili, A.N., Asuzu, M.C., Isah, E.C., and Ogbeide, O., 2004, Job satisfaction and psychological health of doctors at the University of Benin Teaching Hospital. Occupational Medicine, 54, 400-403.

[17] Ghazali, S.S., Shah, I.A., Zaidi, S.A., and Tahir, M.H., 2007, Job satisfaction among doctors working at the teaching hospital of Bahawalpur, Pakistan. Journal of Ayub Medical College Abbottabad, 19(3), 42-5. Retrieved from

https://www.jamc.ayubmed.edu.pk/index.php/jamc/a rticle/view/5030. 
[18] Okaro, O.A., Eze, C.U., and Ohagwu, C.C., 2010, Survey of job satisfaction among Nigerian radiographers in south-eastern Nigeria. Euro $J \mathrm{Sci}$ Res., 39, 448-56.

[19] Kalamawei, I., Abeki, S., and Dienye, P.O., 2016, Determination of factors that influence job satisfaction among health workers in Southern Nigeria. Journal of Hospital Administration, 5(2), 614. https://doi.org/10.5430/jha.v5n2p6.

[20] Gyang, M.D., Dankyau, M., Gidado, S., Gyang, B.A., and Madaki, A.J.K., 2018, Job satisfaction among healthcare workers at a district hospital in Plateau State, Nigeria. Journal of Medicine in the Tropics, 20(2), 111-116. DOI: 10.4103/jomt.jomt_11_18.

[21]Chirdan, O.O, Akosu, J.T., Ejembi, C.L., Bassi, A.P, and Zoakah, A.I., 2009, Perceptions of working conditions amongst health workers in state-owned facilities in Northeastern Nigeria. Ann AfrMed., 8(4), 243-9. DOI: 10.4103/1596-3519.59579.

[22] Omolase, C.O., Seidu, M.A., Omolase, B.O., and Agborubere, D.E., 2010, Job satisfaction amongst Nigerian ophthalmologists: An exploratory study. Libyan J Med, 5, 4629 - DOI: 10.4176/091010.

[23] Yakasai, I.A., Ugwa, E.A., and Abubakar, I.S., 2013, Job Satisfaction among Resident Doctors in a Tertiary Healthcare Facility in Northern Nigeria; A Cross Sectional Survey. Trop J ObstetGynaecol. 30 (1), 89-96.
[24]Pilay, R., 2009, Work satisfaction of professional nurses in South Africa: a comparative analysis of the public and private sectors. Human Resources for Health, 7, 7-15. Retrieved from: http://www.humanresourceshealth.com/content/7/1/15. Accessed 20/05/2020.

[25] Abdullah, M., and Nahla, A.J.K., 2006, Job satisfaction among primary health care physicians and nurses in Al- Madinah Al-Munawwara. J Egypt Public Health Assoc., 81(3-4), 165-80.

[26] Kumar, R., Ahmed, J., Shaikh, B.T., Hafeez, R., and Hafeez, A., 2014, Job satisfaction among public health professionals working in public sector: a cross sectional study from Pakistan. BMC Human Resources for Health, 11, 2. Doi: 10.1186/14784491-11-2.

[27] Helalah, A.M., Jorissen, S.L., Niaz, K., Mansour, A., and Al Qarni, A., 2014, Job Stress and job satisfaction among health care professionals. European Scientific Journal, 10 (32), 156-173.

[28] Katja, G., et al.., 2015, Working atmosphere and job satisfaction of healthcare staff in Kenya: An exploratory study. Biomed Research International, 2015(256205), 1-7.

http://dx.doi.org/10.1155/2015/256205 